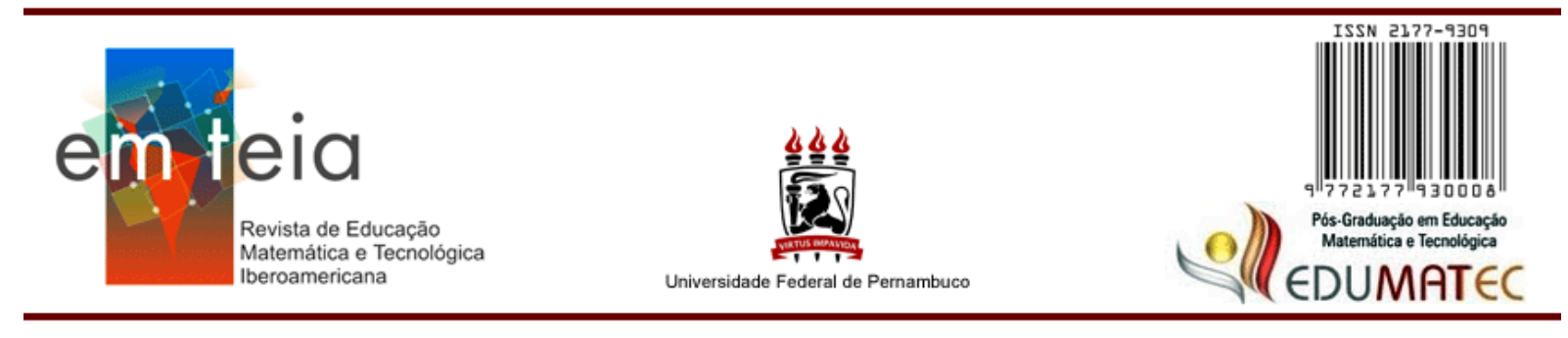

\title{
ASPECTOS EPISTEMÓLOGICOS DAS DISCUSSÕES SOBRE FORMAÇÃO DE PROFESSORES EM TRABALHOS PUBLICADOS NA CONFERÊNCIA NACIONAL SOBRE MODELAGEM NA EDUCAÇÃO MATEMÁTICA
}

\section{EPISTEMOLOGICAL ASPECTS OF DISCUSSIONS ON TEACHER TRAINING IN PAPERS PUBLISHED AT THE NATIONAL CONFERENCE ON MODELING IN MATHEMATICAL EDUCATION}

Cristiane Elise Reich Matioli

Mestranda em Educação em Ciências e Educação Matemática - PPGECEM, Paraná, Brasil Professora da Secretaria de Educação do Paraná - SEED e do Centro de Ensino Superior de Foz do Iguaçu - CESUFOZ cris.matioli@gmail.com

Gabriele de Sousa Lins Mutti Doutoranda em Educação em Ciências e Educação Matemática - PPGECEM, Paraná, Brasil Professora da Secretaria de Educação do Paraná - SEED e do Centro de Ensino Superior de Foz do Iguaçu - CESUFOZ gabi_mutti@hotmail.com

Tiago Emanuel Klüber Doutor em Educação Cientifica e Tecnológica pela Universidade Federal de Santa Catarina, Brasil Professor Adjunto da Universidade Estadual do Oeste do Paraná tiagokluber@gmail.com

\section{Resumo}

Neste artigo discutimos aspectos epistemológicos concernentes à formação continuada de professores mencionados nos trabalhos publicados na Conferência Nacional sobre Modelagem na Educação Matemática (CNMEM) no período de 2005 a 2015. A pesquisa foi orientada pela interrogação: $O$ que se mostra, epistemologicamente, das discussões apresentadas pelos autores que discorrem sobre formação de professores, mencionados nos trabalhos sobre formação continuada publicados na CNMEM? Esta foi estabelecida sob a abordagem qualitativa, segundo uma perspectiva fenomenológica-hermenêutica. Foram analisados 18 (dezoito) trabalhos publicados na conferência. A análise revelou que não há unanimidade de compreensão quanto aos encaminhamentos que devem ser adotados no contexto da formação continuada de professores e, do mesmo modo, no da formação continuada em Modelagem, o que explicita a necessidade de intensificação de esforços da comunidade acadêmica no sentido de buscar pelo estabelecimento de parâmetros, mesmo que mínimos, que busquem harmonizar o diálogo entre essas instâncias, visando o aprimoramento de iniciativas de formação que favoreçam a prática recorrente de modelagem dos professores.

Palavras-chave: Formação de professores. Educação Matemática. Modelagem Matemática. Fenomenologia. Epistemologia. 


\begin{abstract}
In this article we discuss epistemological aspects concerning the continuing education of teachers mentioned in the works published at the National Conference on Modeling in Mathematical Education (CNMEM) in the last decade. The research was guided by interrogation: What is shown, epistemologically, of the discussions presented by the authors who discuss the formation of teachers, mentioned in the work on continuing education published in CNMEM? This was established under the qualitative approach, according to a phenomenological-hermeneutic perspective. Eighteen papers published in the conference were analyzed. The analysis revealed that there is no unanimity of comprehension regarding the referrals that should be adopted in the context of the continuing education of teachers and, likewise, in the continuous formation in modeling, which explains the need for intensification of Efforts of the academic community to seek for the establishment of parameters, even if minimum, which seek to harmonize dialogue between these bodies, aiming at the improvement of training initiatives that favor the recurrent practice of Teacher modelling.
\end{abstract}

Keywords: Teacher training. Mathematics education. Mathematical modelling. Phenomenology. Epistemology.

\title{
Introdução
}

A Modelagem Matemática ${ }^{1}$, enquanto tendência da Educação Matemática, passou a ser considerada na literatura como promissora, por favorecer o trabalho com a matemática a partir de situações do cotidiano, por incentivar a participação ativa do aluno no processo de aprendizagem e possibilitar que o professor assuma a postura de mediador (BURAK, 2004; ALMEIDA; SILVA; VERTUAN, 2012).

Dentre os autores que têm incentivado a utilização da Modelagem Matemática em sala de aula estão Barbosa (2003, 2004) e Burak (2004). Embora o trabalho com a Modelagem Matemática na escola seja defendido na literatura como promissor do ponto de vista da aprendizagem da Matemática, a maior parte dos professores ainda se mostra insegura para utilizá-la, talvez pelo fato de ela solicitar encaminhamentos pedagógicos distintos daqueles que os professores estão habituados a adotar em suas aulas (SILVEIRA; CALDEIRA, 2012); notadamente, aqueles que priorizam a resolução de exercícios e a exposição de conteúdos de forma tradicional. Ressaltamos que o ensino tradicional é, de acordo com Santos (2011), caracterizado por aulas centradas no professor, sendo que ele define quais serão os conteúdos repassados aos alunos, assim como a organização de como será efetuado o processo de ensino-aprendizagem.

\footnotetext{
${ }^{1}$ Esclarecemos que no decorrer do texto utilizaremos as expressões Modelagem Matemática e Modelagem como sinônimos.
} 
Essa insegurança pode ser proveniente do fato de a Modelagem Matemática não ter sido trabalhada durante a formação inicial desses professores e, nos casos em que ela foi contemplada, acabou sendo restringida a uma disciplina, cuja duração foi limitada (OLIVEIRA, 2016). No que diz respeito à formação continuada, no caso específico das ofertadas pela Secretaria de Estado e Educação do Paraná - SEED, no período de 2005 a 2015, a Modelagem Matemática tem sido pouco considerada (CARARO; MUTTI; KLÜBER, 2015).

Os aspectos supracitados revelam os motivos da formação de professores em Modelagem Matemática, tanto a inicial quanto a continuada, ser considerada de máxima importância para que a Modelagem Matemática chegue à escola e possa ser adotada pelos professores de Matemática (BARBOSA, 2001). Segundo Bisognin e Bisognin (2012, p. 1065), em se tratando de formação de professores em Modelagem Matemática há a necessidade

[...] de o professor familiarizar-se com esta metodologia para agir com segurança em sala de aula e provocar uma mudança efetiva em sua prática docente. Para isso, é necessária a introdução da Modelagem nos cursos de formação inicial e continuada e sua utilização nas disciplinas desses cursos, no sentido de proporcionar a vivência de diferentes experiências [...].

Podemos dizer, portanto, que é relevante que o professor vivencie experiências com a Modelagem Matemática em contextos de formação para que possa se sentir seguro ao utilizála em sala de aula (MUTTI, 2016; MARTINS, 2016).

Ainda que se tenha certa clareza da relevância da formação de professores para a adoção da Modelagem no contexto escolar e, para além disso, tenham sido ampliadas as iniciativas de pesquisas dirigidas a essa temática no contexto da comunidade da Educação Matemática (TAMBARUSSI; KLÜBER, 2014), um aspecto que tem se destacado como um espaço aberto para novas investigações é o fato de se explicitarem dessas pesquisas diferentes compreensões no que diz respeito à formação continuada de professores em Modelagem e ao modo "como" ela pode ser encaminhada.

Essas diferentes compreensões explicitam-se nas discussões sobre formação de professores apresentadas pelos autores tomados como referenciais teóricos das pesquisas desenvolvidas no contexto da comunidade de Modelagem Matemática. Interessados em aprofundar reflexões sobre essas discussões, voltamo-nos para os trabalhos sobre formação continuada de professores em Modelagem Matemática publicados na Conferência Nacional sobre Modelagem Matemática na Educação Matemática (CNMEM), interrogando: O que se 
mostra, epistemologicamente, das discussões apresentadas pelos autores que discorrem sobre formação de professores, mencionados nos trabalhos sobre formação continuada publicados na CNMEM? Esclarecemos que ao dizermos formação de professores referimo-nos tanto aos autores que discorrem sobre formação de professores de um modo geral como àqueles que dizem, especificamente, sobre formação em Modelagem. Na seção "Trajetória metodológica de investigação" apresentamos nominalmente os autores que foram considerados nesta pesquisa.

Um dos fatores que avalizam a pertinência do desenvolvimento de pesquisas como a que apresentamos nesse artigo é a necessidade, mencionada por Oliveira (2016), de pesquisas que atentem para os referenciais teóricos adotados nas investigações voltadas à Modelagem Matemática.

Visando esclarecer ao leitor o caminho que percorremos durante a realização dessa investigação, explicitaremos, no próximo subtítulo, a trajetória de pesquisa que foi orientada pela interrogação supracitada.

\section{Trajetória metodológica de investigação}

Explicitar os aspectos metodológicos relacionados à trajetória de investigação que percorremos é, conforme Bicudo (2011, p. 11), preponderante no sentido de conferir à pesquisa "graus de confiança". Nesse sentido, damos o primeiro passo, explicitando que assumimos a pesquisa segundo uma visão fenomenológica.

Assumir a postura fenomenológica de investigação implica em buscar por compreensões que levem à essência do fenômeno focado, sem que nos apeguemos a “[...] conceitos e concepções teóricas prévias que possam postular o que ele é" (BICUDO, 2010, p. 41). Isso solicita que descrevamos um movimento que envolve "perseguir [uma] interrogação de modo [...] sistemático sempre andando em torno dela, buscando as suas dimensões [...] que se doam à compreensão" (PAULO; AMARAL; SANTIAGO, 2010, p. 74).

Sendo assim, nesse artigo, fomos, como é próprio da postura de investigação que assumimos, orientados por uma interrogação: $O$ que se mostra, epistemologicamente, das discussões apresentadas pelos autores que discorrem sobre formação de professores, mencionados nos trabalhos sobre formação continuada publicados na CNMEM? No quadro 1 apresentamos os autores que dizem sobre formação de professores, seja formação em geral 
ou formação em Modelagem Matemática mencionados como referenciais teóricos nos trabalhos sobre formação continuada analisados.

Quadro 1 - Autores que discorrem sobre formação de professores mencionados nos trabalhos sobre formação continuada publicados na CNMEM

\begin{tabular}{|c|c|}
\hline Formação de professores em geral & Formação de professores em Modelagem Matemática \\
\hline Alarcão (2010) & Almeida e Dias (2007) \\
\hline Boa Vida e Ponte (2002) & Caldeira (2007) \\
\hline Fiorentini (2004) & Dias (2005) \\
\hline Imbérnon (2010) & Oliveira (2007) \\
\hline Modesto (2002) & Oliveira (2010) \\
\hline Nóvoa (1991) & Oliveira e Barbosa (2011) \\
\hline Nóvoa (1992) & \\
\hline Ponte (1992) & \\
\hline Schön (2000) & \\
\hline
\end{tabular}

Fonte: Os autores.

Destacamos que o interesse em pesquisar a formação continuada em Modelagem Matemática e de olharmos, especificamente, para essa conferência se deve, respectivamente, ao fato de estarmos inseridos em um contexto de formação continuada em Modelagem Matemática desde o ano de 2015 e por fazermos parte de um grupo de pesquisa cujas discussões e investigações se voltam a essa temática e por termos a compreensão de que CNMEM tem se configurado, desde o ano de 1999 (quando ocorreu sua primeira edição), como o mais relevante lócus de discussão e divulgação dessa tendência no contexto da Comunidade da Modelagem Matemática.

Cabe ressaltar que a formação continuada em Modelagem Matemática da qual fazemos parte está vinculada ao projeto de extensão Formação de Professores em Modelagem Matemática na Educação Matemática, aprovado em 28/10/2015 sob o parecer 087/2015CCET, da Universidade Estadual do Oeste do Paraná. Ocorre no município de Foz do Iguaçu com a participação de 11 professores da Educação Básica.

Diante disso e tomando como norte a referida interrogação, iniciamos o levantamento dos trabalhos publicados nas categorias "Comunicação Científica" e "Relato de Experiência", nas seis últimas edições da CNMEM, de 2005 a 2015, o que nos permitiu elencar um total de 350 trabalhos. Foram considerados para análise as edições do evento que ocorreram nos anos de 2005 a 2015, uma vez que as três primeiras edições (1999, 2001 e 2003) não estão disponíveis e, até o momento da produção deste artigo, os anais da edição de 2017 ainda não haviam sido publicados. 
Com os trabalhos organizados, passamos ao levantamento dos que poderiam dizer de nossa interrogação, olhando para seus títulos, resumos e palavras-chave, utilizando como descritores de busca as expressões: "formação continuada", "formação continuada de professores", "formação contínua" e "formação de professores".

Desse primeiro movimento emergiram 23 trabalhos, sendo 19 comunicações científicas e 4 relatos de experiência, que foram lidos integralmente à luz de nossa interrogação de pesquisa, de modo que após essa leitura 18 se mostraram convergentes à nossa interrogação. O quadro 2 apresenta os textos que foram considerados para essa investigação.

Quadro 2 - Textos considerados para investigação

\begin{tabular}{|c|c|c|c|c|}
\hline Código & Título do Artigo & Autor (es) & Objetivo & Edição \\
\hline A1 & $\begin{array}{l}\text { A relação entre } \\
\text { Modelagem Matemática } \\
\text { e a prática colaborativa } \\
\text { na formação continuada } \\
\text { de professores }\end{array}$ & $\begin{array}{l}\text { Ilaine da Silva Campos } \\
\text { e Ana Virgínia de } \\
\text { Almeida Luna }\end{array}$ & $\begin{array}{l}\text { Discutir a relação entre a } \\
\text { Modelagem e a prática colaborativa } \\
\text { na formação continuada de } \\
\text { professores de Matemática }\end{array}$ & VI \\
\hline A2 & $\begin{array}{l}\text { Considerações iniciais } \\
\text { sobre um curso de } \\
\text { Modelagem matemática } \\
\text { em ambientes virtuais }\end{array}$ & $\begin{array}{l}\text { Carlos Roberto Ferreira } \\
\text { e Dionísio Burak }\end{array}$ & $\begin{array}{lrr}\text { Apresentar } & \text { considerações iniciais } \\
\text { sobre um curso de formação } \\
\text { continuada em Modelagem } \\
\text { Matemática, } \\
\text { modalidade de Educação a Distância }\end{array}$ & VI \\
\hline A3 & $\begin{array}{l}\text { O grupo colaborativo } \\
\text { em modelagem } \\
\text { matemática e a } \\
\text { formação continuada de } \\
\text { professores: possíveis } \\
\text { transformações de uma } \\
\text { prática }\end{array}$ & Roberta Mota & $\begin{array}{l}\text { Compreender a influência do Grupo } \\
\text { Colaborativo em Modelagem } \\
\text { Matemática (GCMM) na formação } \\
\text { continuada de professores de } \\
\text { Matemática na educação básica entre } \\
\text { os anos de } 2007 \text { e } 2012 \text {. }\end{array}$ & VIII \\
\hline A4 & $\begin{array}{l}\text { A ação pedagógica em } \\
\text { ambientes de } \\
\text { modelagem Matemática: } \\
\text { uma discussão a partir } \\
\text { da Própria prática }\end{array}$ & $\begin{array}{l}\text { Luzinete de } \text { Oliveira } \\
\text { Mendonça e Celi } \\
\text { Espasandin Lopes }\end{array}$ & $\begin{array}{l}\text { Discutir a ação pedagógica em } \\
\text { ambientes de modelagem } \\
\text { Matemática, em uma abordagem } \\
\text { qualitativa. }\end{array}$ & VII \\
\hline A5 & 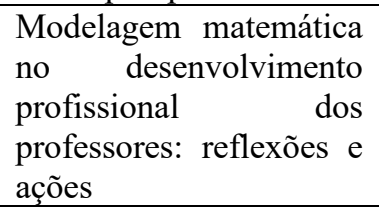 & $\begin{array}{l}\text { Luzinete de } \\
\text { Mendonça e } \\
\text { Espasandin }\end{array}$ & $\begin{array}{l}\text { Discutir a utilização da Modelagem } \\
\text { Matemática na formação continuada } \\
\text { de professores de Matemática. }\end{array}$ & VIII \\
\hline A6 & $\begin{array}{l}\text { Experienciando a } \\
\text { modelagem matemática } \\
\text { em formação continuada }\end{array}$ & $\begin{array}{l}\text { Roberta } r \text { Modesto } \\
\text { Braga, Maria Lídia } \\
\text { Paula Ledoux, Edilene } \\
\text { Farias Rozal e Adilson } \\
\text { de Oliveira Espírito } \\
\text { Santo }\end{array}$ & $\begin{array}{l}\text { Analisar nas produções de alunos, } \\
\text { em formação continuada, o fazer } \\
\text { Modelagem Matemática. }\end{array}$ & VIII \\
\hline A7 & 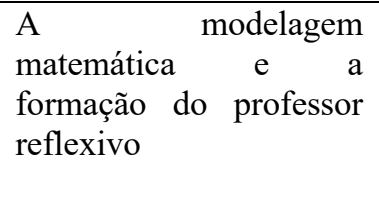 & $\begin{array}{l}\text { Claudia Carreira Rosa e } \\
\text { Lilian Akemi Kato }\end{array}$ & $\begin{array}{l}\text { Defender a utilização de atividades } \\
\text { de Modelagem Matemática no } \\
\text { âmbito da sala de aula como uma } \\
\text { forma de levar o professor a repensar } \\
\text { sua prática }\end{array}$ & VIII \\
\hline A8 & $\begin{array}{l}\text { Modelagem matemática: } \\
\text { experiência com o tema }\end{array}$ & $\begin{array}{l}\text { Larissa Rosa Santos e } \\
\text { Vanilde Bisognin }\end{array}$ & 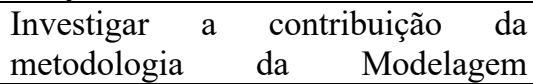 & VIII \\
\hline
\end{tabular}




\begin{tabular}{|c|c|c|c|c|}
\hline & $\begin{array}{l}\text { água em um curso de } \\
\text { formação de professores }\end{array}$ & & $\begin{array}{l}\text { Matemática } \text { no ensino } \mathrm{e} \\
\text { aprendizagem } \\
\text { matemáticos relacionados com o } \\
\text { tema água }\end{array}$ & \\
\hline A9 & $\begin{array}{l}\text { Modelagem matemática } \\
\text { em curso de formação } \\
\text { continuada }\end{array}$ & $\begin{array}{l}\text { Alvino Alves Sant'Ana } \\
\text { e Marilaine de Fraga } \\
\text { Sant'Ana }\end{array}$ & $\begin{array}{l}\text { Relatamos e analisamos uma prática } \\
\text { desenvolvida em um curso de } \\
\text { formação continuada. }\end{array}$ & IX \\
\hline $\mathbf{A 1 0}$ & $\begin{array}{l}\text { Modelagem matemática } \\
\text { na formação continuada } \\
\text { de professores: uma } \\
\text { análise a partir das } \\
\text { produções do ENEM } \\
2013 \text { e EPREM } 2014\end{array}$ & $\begin{array}{l}\text { Ariel Cardoso Silva, } \\
\text { Jeferson Takeo Paduan } \\
\text { Seki, Rudolph dos } \\
\text { Santos Gomes Pereira, } \\
\text { Bárbara Nivalda } \\
\text { Palharini Alvim Sousa } \\
\text { Robim e Bianca de } \\
\text { Oliveira Martins }\end{array}$ & $\begin{array}{l}\text { Identificar e analisar artigos } \\
\text { publicados sobre modelagem } \\
\text { matemática e formação continuada } \\
\text { de professores. }\end{array}$ & IX \\
\hline A11 & 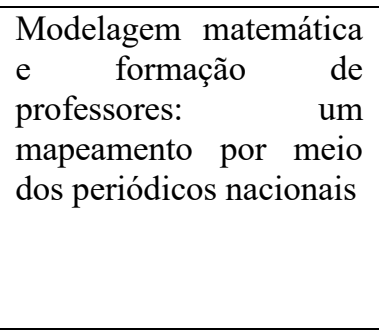 & $\begin{array}{lr}\begin{array}{l}\text { Bianca de } \\
\text { Martins, }\end{array} \text { Bárbara } \\
\text { Nivalda } \\
\text { Alvim Salharini } \\
\text { Jeferson Takeo Paduan } \\
\text { Seki, Rudolph dos } \\
\text { Santos Gomes Pereira e } \\
\text { Ariel Cardoso da Silva }\end{array}$ & $\begin{array}{l}\text { Responder a seguinte problemática: } \\
\text { De } 2010 \text { a 2014, qual foi a } \\
\text { quantidade de trabalhos publicados } \\
\text { nas revistas científicas brasileiras, no } \\
\text { que tange a formação de professores } \\
\text { e a modelagem matemática na } \\
\text { Educação Matemática }\end{array}$ & IX \\
\hline A12 & $\begin{array}{l}\text { Modelagem nas ciências } \\
\text { e matemática: percepção } \\
\text { de professores em } \\
\text { formação continuada }\end{array}$ & 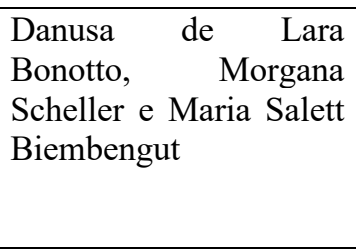 & $\begin{array}{l}\text { Compreender as percepções dos } \\
\text { professores do Ensino Médio, de } \\
\text { diferentes áreas do conhecimento, } \\
\text { envolvidos em uma atividade de } \\
\text { Modelagem na Educação - } \\
\text { Modelação. }\end{array}$ & IX \\
\hline A13 & $\begin{array}{lr}\text { Percepções } & \text { dos } \\
\text { professores } & \text { em } \\
\text { atividades } & \text { de } \\
\text { Modelagem } & \text { matemática } \\
\text { na formação continuada }\end{array}$ & $\begin{array}{lr}\text { Morgana Scheller, } \\
\text { Danusa de } \text { Lara } \\
\text { Bonotto e Maria Salett } \\
\text { Biembengut. }\end{array}$ & $\begin{array}{l}\text { Responder a seguinte problemática: } \\
\text { como os professores em formação } \\
\text { continuada, vivenciando atividades } \\
\text { de Modelagem Matemática (MM), } \\
\text { percebem este processo e como } \\
\text { ocorre o movimento de formador e } \\
\text { professores na MM? }\end{array}$ & IX \\
\hline A14 & $\begin{array}{l}\text { Que professor } \\
\text { constrói com } \\
\text { Modelagem } \\
\text { Matemática? }\end{array}$ & $\begin{array}{l}\text { Maria Isaura de } \\
\text { Albuquerque Chaves e } \\
\text { Adilson } \quad \text { Oliveira } \\
\text { Espírito Santo }\end{array}$ & $\begin{array}{l}\text { Compreender como se dá a } \\
\text { formação do professor no contexto } \\
\text { da Modelagem, por meio da } \\
\text { pesquisa sobre as bases } \\
\text { epistemológicas do professor. }\end{array}$ & VI \\
\hline A15 & $\begin{array}{l}\text { Um estudo sobre o } \\
\text { desenvolvimento } \\
\text { profissional do professor } \\
\text { num programa de } \\
\text { formação } \\
\text { Modelagem Matemática }\end{array}$ & $\begin{array}{l}\text { Michele Regiane Dias e } \\
\text { Lourdes Maria Werle } \\
\text { Almeida }\end{array}$ & \begin{tabular}{lcrr} 
Abordar & o & \multicolumn{2}{l}{ desenvolvimento } \\
profissional do & professor & num \\
programa de & formação & em \\
Modelagem & Matemática. &
\end{tabular} & IV \\
\hline RE1 & $\begin{array}{l}\text { Modelagem } \\
\text { na formação } \\
\text { Continuada: um olhar de } \\
\text { professores sobre a } \\
\text { questão do câncer de } \\
\text { mama }\end{array}$ & $\begin{array}{lr}\text { Vivilí } & \text { Maria } r \begin{array}{r}\text { Silva } \\
\text { Gomes, } \\
\text { Augusto }\end{array} \text { Soares, Carla } \\
\text { Cristina } & \text { Castilho, } \\
\text { Camilo } & \text { Misura; } \\
\text { Adilson } & \text { Donizete } \\
\text { Terazan } & \end{array}$ & $\begin{array}{l}\text { Apresentar resultados preliminares e } \\
\text { possibilidades de encaminhamento } \\
\text { para a resolução do problema em } \\
\text { foco, geradas nas discussões } \\
\text { estabelecidas por um grupo de } \\
\text { professores da Educação Básica }\end{array}$ & VI \\
\hline RE2 & $\begin{array}{l}\text { Modelagem matemática: } \\
\text { um estudo na viação } \\
\text { Férrea de Santa Maria }\end{array}$ & $\begin{array}{l}\text { Edineia Raquel Benetti, } \\
\text { Karine Faverzani } \\
\text { Magnago, Daniele } \\
\text { Delle Méa da Silva e } \\
\text { Kátia Fogaça Martins } \\
\end{array}$ & $\begin{array}{l}\text { O objetivo desse trabalho é relatar a } \\
\text { experiência de Modelagem } \\
\text { Matemática realizada em um curso } \\
\text { de formação continuada de } \\
\text { professores que consistiu da }\end{array}$ & VI \\
\hline
\end{tabular}




\begin{tabular}{|c|l|l|l|l|l|}
\hline & & & delimitação do tema motivador Trem & \\
\hline RE3 & Modelagem matemática & Jonson Ney Dias da & Apresentar resultados parciais de & VII \\
& e a formação continuada & Silva, Carlos Henrique & uma atividade proposta pelo projeto & \\
& de Professores da & Carneiro e Flávia & intitulado "Novos olhares sobre a & \\
& educação básica: & Cristiana de Macêdo & formação de professores e estudantes & \\
& Programa novos talentos & Santana & dacação básica” & \\
\hline
\end{tabular}

Fonte: Os autores.

Após o levantamento dos trabalhos que se mostraram convergentes a nossa interrogação, passamos para a constituição das unidades de significado que são "[...] recortes considerados significativos pelo pesquisador, dentre os vários pontos aos quais a descrição pode levá-lo" (GARNICA, 1999, p. 20). A figura 1 apresenta um exemplo de unidade de significado e o excerto de texto ao qual ela está vinculada:

Figura 1 - Unidade de significado e excerto do texto que lhe é correspondente

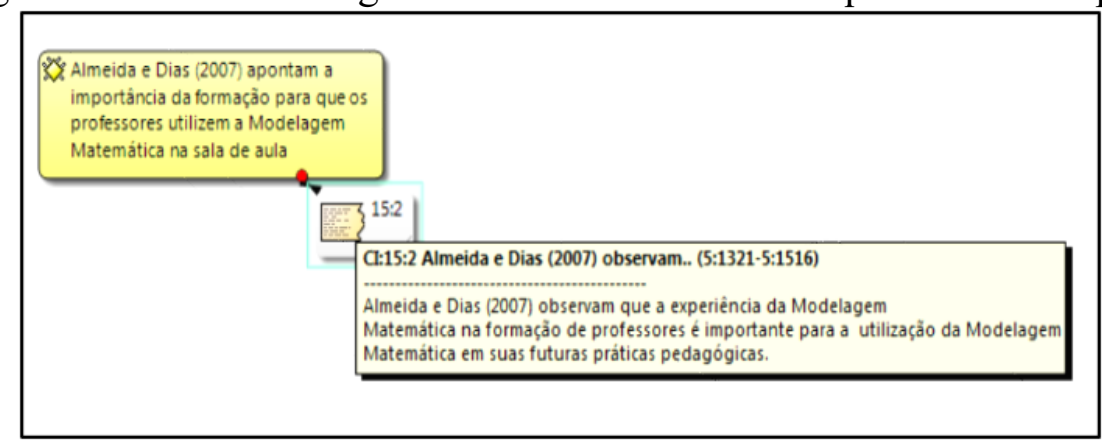

Fonte: Os autores.

$\mathrm{Na}$ sequência da investigação, buscamos analisar, cuidadosamente, cada uma das unidades de significado estabelecidas num esforço de explicitar as "[...] confluências que poderiam ser estabelecidas entre as asserções presentes [entre elas]" (MUTTI, 2016, p. 50, inserção nossa) intencionando construir “grandes categorias ou Núcleos de Ideias" (BICUDO; KLÜBER, 2011, p. 5). Desse movimento emergiram as seguintes categorias: C1: "Sobre as discussões dos autores mencionados nos trabalhos da CNMEM em relação à formação continuada em Modelagem Matemática e as experiências com atividades de Modelagem Matemática nesses contextos", C2: "Sobre as compreensões de 'formação continuada' que se explicitam das discussões dos autores mencionados nos trabalhos da CNMEM" e C3: "Sobre o que dizem os autores mencionados nos trabalhos da CNMEM em relação à relevância e as expectativas dos professores ao participarem de grupos nos contextos de formação continuada em Modelagem Matemática".

Essas categorias foram então descritas. A descrição na perspectiva fenomenológica de investigação visa "[relatar], de modo direto, a experiência vivida por um sujeito em situação 
de vivenciar o fenômeno focado e destacado como importante em relação à interrogação formulada" (BICUDO, 2011, p. 55-56, inserção nossa). Essa descrição foi, posteriormente, refletida de tal modo que pudéssemos compreender em maior profundidade o que elas dizem acerca do fenômeno.

A busca pela essência do fenômeno se deu por meio de um "[...] movimento hermenêutico, realizado no círculo existencial-hermenêutico gera, a partir de compreensões primeiras, compreensões e interpretações outras, que são engendradas e engendram compreensões/interpretações cada vez mais apuradas" (GARNICA; BICUDO, 1994, p. 97).

Toda a trajetória de investigação anteriormente mencionada foi otimizada com o auxílio do software Atlas.ti ${ }^{2}$ Ele é uma ferramenta de pesquisa qualitativa sujeita ao trabalho do pesquisador, e como bem menciona Klüber (2014), adequada também à abordagem na perspectiva fenomenológica.

Esclarecidos os aspectos relacionados à trajetória metodológica de investigação que descrevemos, passaremos, na sequência, à descrição e interpretação das categorias que dela emergiram.

\section{Descrição e interpretação das categorias}

A categoria aberta C1: "Sobre as discussões dos autores mencionados nos trabalhos da CNMEM em relação à formação continuada em Modelagem Matemática e as experiências com atividades de Modelagem Matemática nesses contextos", possui 19 unidades de significado que estão associadas aos documentos primários A1, A4, A5, A8, A9, A10, A13, A14, RE2 e RE3.

Dentre as compreensões que se explicitam das discussões apresentadas pelos autores que discorrem sobre formação de professores estão as de que a formação continuada em Modelagem Matemática precisa contemplar questões teóricas, metodológicas e práticas, de tal modo que os professores sejam indagados sobre a pertinência e a possibilidade de trabalhar com a Modelagem Matemática e a de que os professores necessitam ter contato com a Modelagem Matemática sob diferentes perspectivas, vivenciando experiências com ela, inclusive, como alunos, para que possam, posteriormente, optar pelas que são convergentes às suas necessidades docentes.

\footnotetext{
${ }^{2}$ Ressaltamos que possuímos a licença para a utilização desse software.
} 
As discussões apresentadas pelos autores e expressas nas unidades dizem ainda que os contextos de formação podem contribuir para que a Modelagem Matemática seja adotada na escola, uma vez que auxilia os professores a se sentirem seguros para utilizá-la, pois são espaços que incentivam a aquisição não só de aspectos cognitivos, mas também sócio afetivos e culturais associados ao trabalho com a Modelagem Matemática.

A decisão pelo trabalho com a Modelagem Matemática, no entanto, depende, segundo explicitam as unidades, da concepção epistemológica do conhecimento matemático assumida pelos professores. Sendo assim, as experiências com a Modelagem Matemática no contexto da formação podem não ser determinantes para que essa tendência da Educação Matemática seja adotada na sala de aula, ainda que possam contribuir com aquisição de compreensões em relação ao processo de ensino e aprendizagem que podem ser refletidas na escola.

Sobre isso as unidades 10:1, 11:2, 11:4 e 18:10 dizem: "Dias (2005), diz que as experiências incorporadas pelos professores nas formações são adquiridas por processos não somente cognitivos, mas também sócio-afetivos e culturais”, "Almeida e Dias (2007) Oliveira (2007 e 2010) e Oliveira e Barbosa (2011) dizem que é na formação continuada que o professor adquire embasamento teórico para assumir a Modelagem Matemática como uma perspectiva pedagógica”, "Almeida e Dias (2007) dizem que o professor precisa aprender e ensinar utilizando a MM, e para isso precisa passar por uma formação abrangente envolvendo aspectos teóricos, metodológicos e práticos" e "Sobre a formação do professor, Caldeira (2007) diz que a concepção epistemológica sobre matemática que o professor traz consigo influencia a sua prática e consequentemente a aprendizagem dos alunos”.

A categoria aberta C2: "Sobre as compreensões de 'formação continuada' que se explicitam das discussões dos autores mencionados nos trabalhos da CNMEM", possui 24 unidades de significado que estão associadas aos documentos primários A1, A3, A6, A7, A10, A13, A15, RE2 e RE15. De acordo com discussões apresentadas pelos autores que discorrem sobre formação de professores, existem diversos modelos de formação que tomam a formação de professores sob diferentes perspectivas. Dentre elas está a compreensão de que a formação não deve ser entendida como mero treinamento profissional, mas sim, como um processo dinâmico.

Segundo as unidades, a formação de professores deve ser compreendida como um espaço em que o professor pode refletir acerca de sua prática, partilhando experiências e produzindo conhecimentos. Ela é, de acordo com os autores mencionados nos textos considerados, um contexto em que se busca compreender a Matemática com intuito de 
elaborar situações problemas que contribuam, posteriormente, para que os alunos a utilizem para resolver situações do cotidiano.

Isso evidencia o que entendemos como uma mudança epistemológica na área de Matemática, uma vez que há um cuidado em pensar o ensino da Matemática na formação de professores para além da axiomatização e da lógica voltando-a, por outro lado, para seus aspectos práticos e para a busca por práticas pedagógicas que permitam aos alunos tomar a Matemática como uma área do conhecimento plena de significado. Quando dizemos significado referimo-nos ao sentido atribuído pelos alunos aos conceitos matemáticos, sentido esse que os permite compreender a Matemática como uma ciência cujas aplicações vão além da formalização e da lógica, que se expressa nas situações-problema cotidianas e na natureza.

Com efeito, um dos aspectos que se destaca das unidades que constituem essa categoria é a compreensão de que a formação pode se dar por meio de grupos colaborativos, em que os professores se ajudam entre si, não havendo uma hierarquia entre eles. Sobre isso as unidades 1:6, 5:3, 7:5, 17:2 e 18:7 dizem: "Boa Vida e Ponte (2002) e Fiorentini (2004) apontam para o significado etimológico da palavra colaboração", "Nóvoa (1992) diz que a formação não se constrói por acúmulo de cursos mais sim por meio de um trabalho reflexivo sobre as práticas", "Para Ponte (1992) a formação deve ser comprometida com um processo de troca e produção coletiva, oportunizando a partilha de aprendizagem”, "De acordo com Almeida e Dias (2007), pensar em formação de professores de matemática é pensar em situações que oportunizam o professor a ter uma compreensão significativa da matemática para serem capazes de elaborar situações para que os alunos matematizem a realidade” e "Para Modesto (2002), a formação é entendida como uma atividade reflexiva sobre o saber e a prática”.

A categoria aberta C3: "Sobre o que dizem os autores mencionados nos trabalhos da CNMEM em relação à relevância e as expectativas dos professores ao participarem de grupos nos contextos de formação continuada em Modelagem Matemática", possui 40 unidades de significado que estão associadas aos documentos primários A1, A2, A6, A7, A10, A11, A12, A13, A15, RE1 e RE3.

As unidades de significado pertencentes a essa categoria mencionam que a busca pela participação em grupos nos contextos de formação se dá de forma espontânea e que existe uma relação de confiança entre os pares, no sentido de juntos buscarem momentos de reflexão acerca das dificuldades e dos problemas vivenciados em suas práticas pedagógicas, sendo essas algumas das expectativas dos professores quando buscam fazer parte de um grupo. 
As unidades de significado pertencentes a essa categoria mencionam ainda que a formação de professores deve seguir a perspectiva de racionalidade prática como mencionada na unidade 5:2, valorizando o ser humano como criativo, capaz de aprender e fazer descobertas. Para tanto, se faz relevante, conforme as discussões apresentadas pelos autores que discorrem sobre formação de professores presentes nos textos considerados, que a formação ocorra no próprio ambiente escolar, levando em consideração a realidade e as necessidades da escola, de modo que esteja integrada ao processo de mudança e desenvolvimento curricular.

Sobre isso as unidades 1:2, 2:5, 5:2 e 12:7 dizem: "Fiorentini (2004) destaca que um dos fatores que levam o professor a integrar um grupo é a busca pelo próprio desenvolvimento profissional", "Modesto (2002) diz que na formação deve haver a interação com outros professores, levando em consideração a realidade e necessidades da escola", "Nóvoa (1991) diz que a formação continuada deve ser alinhada com o desempenho dos professores e que as escolas devem ser o lugar de referência" e "Imbérnon (2010), Alarcão (2010) e Schön (2000) defendem o modelo de formação continuada que privilegia a racionalidade prática, a qual admite que o ser humano possui capacidade inata de pensamento e reflexão, sendo assim criativo e não um mero reprodutor de ideias".

\section{Interpretações}

Ao buscarmos por uma hermenêutica do que diz a categoria C1: "Sobre as discussões dos autores mencionados nos trabalhos da CNMEM em relação à formação continuada em Modelagem e as experiências com atividades de Modelagem Matemática nesses contextos", compreendemos que é preponderante que o professor perpasse por momentos de formação que contemplem situações evolvendo a Modelagem Matemática, para que ela chegue ao espaço escolar.

Dentre os aspectos destacados está o de que a formação em Modelagem Matemática deve levar o professor a indagar a possibilidade de trabalhar com ela na escola. Indagar significa "fazer pergunta (s) [a alguém ou a si mesmo]" (HOUAISS, 2017, s.p.). Quando refletimos acerca desse significado entendemos que indagar envolve um movimento que é ao mesmo tempo interno e externo ao professor.

É interno na medida em que solicita que o professor indague a si mesmo, ou seja, que reflita acerca de suas concepções em relação ao ensino, à sua prática pedagógica, ao seu 
contexto particular de trabalho e seus alunos, de modo que possa considerar o trabalho com a Modelagem Matemática, partindo de suas próprias necessidades e afinidades.

Esse movimento é também externo ao professor, pois envolve o indagar a alguém, sentença que exprime a ideia de dirigir-se a outros em busca de diálogo. Esses outros envolvem, notadamente, os pares da escola, uma vez que juntos podem reunir esforços para fazer da Modelagem Matemática uma prática frequente em sala de aula. Mas podem referir-se ainda à literatura no âmbito da Modelagem Matemática, aos eventos da área e aos pesquisadores que buscam estabelecer parcerias com a escola, no sentido de contribuir para que os professores se familiarizem com essa tendência a ponto de se sentirem dispostos a adotá-la.

As discussões apresentadas pelos autores que discorrem sobre formação de professores presentes nos artigos analisados revelam ainda que a participação do professor em ambientes de formação não implica, taxativamente, na adoção da Modelagem Matemática à sala de aula. Para que isso ocorra é necessário que o professor sinta segurança e confiança em adotar a Modelagem Matemática na sua prática, pois a sua inserção no contexto escolar exige uma mudança de postura por parte do professor. Isso revela que a formação é tomada, epistemologicamente, à parte. Em outras palavras, não entende que seja responsabilidade da formação atribuir segurança e confiança.

Para tanto, talvez os professores precisem de apoio. Martins (2016), Mutti (2016) e Klüber (2017) mencionam que a participação continuada dos professores no contexto de grupos de estudo, no interior das escolas, pode ajudá-los a encontrar no grupo suporte emocional e segurança, aspectos que estão intrisecamente associados ao fato de terem a possibilidade de fazer parte de um coletivo de pensamento em Modelagem Matemática (MUTTI, 2016; KLÜBER, 2017), em que circulem ideias e práticas dirigidas ao trabalho com ela.

De certo modo, a inserção dos professores em contextos de formação com características próximas à supracitada pode auxiliá-los a superar a cultura de isolamento presente na escola (IMBERNÓN, 2009), fornecendo a eles suporte técnico e emocional que os encoraje a desenvolverem atividades de Modelagem Matemática com seus alunos. Essas são necessidades mencionadas nas teorias presentes nos artigos analisados, sendo que emerge de forma destacável o incentivo à participação dos professores em grupos colaborativos que, segundo Fiorentini (2006), tem o objetivo de socializar experiências de sala de aula, discutir 
dificuldades relativas ao ensino e à aprendizagem e refletir a respeito de diferentes metodologias.

Um último aspecto que vem à tona nessa categoria, quando analisada à luz de nossa interrogação de pesquisa, é o destaque dado pelas discussões apresentadas pelos autores que discorrem sobre formação de professores em relação às experiências com a Modelagem Matemática em contextos de formação. Ele nos remete à ideia de que a experiência pode ser tomada como fonte de conhecimento, a qual é discutida por Hessen (1980) quando fala da origem do conhecimento sob a ótica do empirismo ou de posições a ele intermediárias.

Segundo essa compreensão, o conhecimento é exclusivamente elaborado por meio da experiência, o que talvez nos auxilie na compreensão dos motivos que fazem com que ela seja destacada no contexto da formação e da formação em Modelagem Matemática. É digno de nota, entretanto, que as unidades que constituem essa categoria falam do fato de as experiências com a Modelagem Matemática não serem determinantes para que ela chegue à escola.

Nessa perspectiva, podemos dizer que para além dos conhecimentos oriundos da experiência ou daquilo que os autores consideram experiência, os professores possuem conhecimentos intrínsicos, tanto históricos quanto sociais, os quais acabam exercendo influência em suas decisões sobre o trabalho ou não com a Modelagem Matemática na escola. Esses conhecimentos se expressam até mesmo quando eles vivenciam atividades de Modelagem Matemática em contextos de formação, o que nos leva a refletir sobre a asserção presente nessa categoria sobre os professores as tomarem como alunos.

Nesse caso, concordamos com Luna (2012, p. 24) quando diz que “[...] os professores nos espaços de formação quando realizam as tarefas de Modelagem também estabelecem relações com o seu papel em sala de aula”.

Sendo assim, entendemos que a Modelagem Matemática poderá se fazer presente no âmbito da escola a partir do momento em que o professor se sentir incomodado com a sua prática, isto é, quando ele almejar uma mudança no processo de ensino e aprendizagem da Matemática. É relevante, nesse sentido, que a formação de professores em Modelagem Matemática busque conceber o conhecimento humano como constituído tanto da razão como da experiência.

Essas discussões levam-nos às considerações de Hessen (1980) quando diz que a psicologia entende que o conhecimento humano é um produto do fator racional com o fator empírico. Nesse sentido, uma posição criticista, como apontada por Hessen (1980), pode 
ajudar na superação de visões ingênuas sobre mera empiria e mera teoria. A valorização exacerbada da teoria fere a prática e a exacerbação da prática mantém um pragmatismo inócuo.

No que diz respeito à categoria C2: "Sobre as compreensões de 'formação continuada' que se explicitam das discussões dos autores mencionados nos trabalhos da CNMEM", um aspecto que se destaca é a existência, no âmbito educacional, de distintas compreesões sobre a formação continuada de professores. Essas compreensões, ainda que não digam especificamente da Modelagem Matemática, acabam, como vemos nos artigos considerados, sendo frequentemente admitidas quando se busca constituir práticas de formação continuada em Modelagem Matemática, condição que nos move a ponderá-las nesse artigo.

$O$ fato de existirem e circularem distintas compreensões de formação continuada de professores evidencia a ausência de unanimidade quando as questões postas são, por exemplo: o que significa formar professores? Como a formação de professores deve ser encaminhada de modo que ela se reflita positivamente na prática pedagógica dos professores?, sujeitos para os quais ela se dirige. Bicudo e Paulo (2011) já apontaram para essa ausência de unanimidade quando realizam uma metapesquisa dos trabalhos sobre formação de professores publicados no III Seminário Internacional de Pesquisa em Educação Matemática (SIPEM).

Ao pensarmos nessa ausência de unanimidade, um primeiro aspecto que se destaca é o questionamento em relação aos possíveis fatores que a instituem. Severino (2007, p. 6), ao discutir a pesquisa no campo educacional, diz que

[...] os sujeitos humanos envolvidos no processo educacional, são seres empíricos, entidades naturais e sociais, entes históricos [...] Em decorrência disso, a educação passa a ser proposta como processo, individual e coletivo, de constituição da realidade histórica da humanidade[...]A educação, na qualidade de fenômeno da prática histórico-social dos homens, é um processo extremamente complexo. Podese afirmar que esta complexidade decorre tanto de sua integração ao campo dos fenômenos humanos em geral, herdando assim a complexidade do objeto das ciências humanas, como da condição específica de sua historicidade que the confere um caráter de uma realidade em contínua transformação, em incessante devir. Não há como reduzir tudo o que está implicado na educação num único objeto, a ser apreendido e analisado por uma única ciência (SEVERINO, 2007, p. 6).

Analogamente à fala de Severino (2007), podemos dizer que assim como o processo educacional é um fenômeno considerado complexo, em constante transformação, a formação de professores e, mais especificamente, a formação de professores em Modelagem Matemática, inserida no contexto educacional, se constitui de uma multiplicidade de 
elementos: os professores, os alunos, o processo de ensino-aprendizagem, o currículo, as políticas públicas de ensino, a gestão escolar e a comunidade, isso para mencionar apenas parte deles. Esses elementos possuem características e necessidades que lhes são particulares e que, por sua vez, solicitam a reflexão e elaboração de diferentes estratégias de ação pedagógica que acabam se esboçando em distintos modos de compreender e encaminhar a formação continuada de professores. No entanto, essa pluralidade não pode incorrer em esvaziamento da tentativa de ações convergentes e coerentes, que indiquem novos caminhos para a formação.

Um segundo aspecto é mencionado por Bicudo e Paulo (2011), quando dizem que nas pesquisas em Educação Matemática existe uma quantidade significativa de autores que tematizam a formação de professores, evidenciando o interesse deles em compreender de modo mais aprofundado essa temática.

Entendemos, entretanto, que há a necessidade no âmbito da comunidade da Educação Matemática, de serem reunidos esforços no sentido de buscar por critérios de consenso, que se constituam como eixos balizadores comuns, sobre os quais possam ser estruturados diferentes práticas/modelos/programas de formação continuada de professores.

Ainda que a afirmação pareça contraditória um primeiro momento, ela expressa uma necessidade: a de que as particularidades inerentes aos diferentes contextos escolares possam ser atendidas por modelos de formação convergentes a elas. Mas para que esse processo não se reduza a um constante recomeçar, esvaziado dos resultados já obtidos, é preponderante que os modelos/programas de formação sejam construídos com base em critérios balizadores, mesmo que mínimos, que norteiem a elaboração de estratégias de formação.

É necessário que essas questões sejam consideradas com certo cuidado, pois entendemos que a formação de professores não deve se reduzir à ótica positivista, a qual não considera as especificidades dos sujeitos, suas práticas e suas relações no plano individual e coletivo (SERVERINO, 2007). Podemos dizer que o processo educacional e, do mesmo modo, o processo formativo dos professores são práticas histórico-sociais complexas e que estão intrinsicamente relacionadas, não podendo ser, portanto, norteadas de maneira técnica, mecânica.

No que diz respeito à categoria C3: "Sobre o que dizem os autores mencionados nos trabalhos da CNMEM em relação à relevância e às expectativas dos professores ao participarem de grupos nos contextos de formação continuada em Modelagem Matemática, um dos aspectos destacados é que a participação dos professores em grupos nos contextos de 
formação se dá de forma espontânea. Ao buscarmos por uma hermenêutica dessa palavra compreendemos que ela se refere ao "que alguém faz por si mesmo, sem ser incitado ou constrangido por outrem; voluntário" (HOUAISS, 2017, s.p.). Nesse sentido, entendemos que a participação em grupos de formação é um ato que se dá de forma intencional permeado por questões de cunho emocional e psicológico que disparam naquele que se insere ao grupo a disposição altruísta de estar com o outro. Isso mostra que para que o professor possa realmente se sentir parte de um grupo é necessário que ele se integre livremente, sem que se sinta na obrigação de fazê-lo.

Além disso, agir de modo espontâneo revela disposição que, por sua vez, indica o movimento intencional do professor em busca de conhecimentos e vivências com a Modelagem Matemática. Essa disposição não implica na diminuição dos desafios que o professor talvez tenha que enfrentar para adotar a Modelagem Matemática à sua prática, pois elas poderão emergir mesmo que o professor se mostre decidido a fazer isso, uma vez que existem os desafios impostos pelo próprio contexto escolar. Por outro lado, a disposição já pode fornecer um indicativo, uma abertura, mesmo que mínima à Modelagem Matemática.

Ressaltamos, entretanto, que a disposição do professor não desonera a formação de ofertar condições para que o professor adote a Modelagem. A disposição espontânea do professor é relevante, pois revela o movimento autônomo de buscar modificar sua prática. Não devemos deixar de considerar, por outro lado, que alguns professores podem não descrever por conta própria esse movimento, condição que mais uma vez reitera o papel relevante da formação em Modelagem no sentido de fornecer-lhes meios para descrevê-lo.

Outro fator que se mostra das discussões apresentadas pelos autores que discorrem sobre formação de professores mencionadas nos artigos levantados, é a importância do estabelecimento de uma relação de confiança entre os pares nos contextos de formação. Quando buscamos pela etimologia da palavra confiança, encontramos que ela vem do latim confidentia, e um dos seus significados está relacionado ao termo com firmeza (HOUAISS, 2017, p. 1). Nesse sentido, compreendemos que o estabelecimento de uma relação bem estabelecida por laços de confinça entre os pares num contexto de formação de professores poderá fazer com que eles se sintam mais seguros para trabalhar com questões que, em algum momento, tenham condições de se deslocarem de sua zona de conforto, exigindo, portanto, uma possível mudança de suas práticas.

Quando é estabelecida paulatinamente no contexto de um grupo de formação, uma relação de confiança, os professores se sentem mais à vontade durante as discussões e a troca 
de experiências, para exporem suas angústias, dificuldades e anseios enfrentados nos ambientes escolares, mais especificamente no contexto da sala de aula. Além disso, as reflexões estabelecidas nesse momento poderão fazer com que os professores se sintam motivados a, com o apoio dos colegas, trabalhar com práticas que talvez se distanciem das que habitualmente desenvolvem.

Outro aspecto que emergiu das unidades de significado é a afirmação de que a formação continuada de professores deve seguir o princípio da racionalidade prática. Pensemos, inicialmente, na racionalidade. Japiassú e Marcondes (2001, p. 1) dizem que ela "é a característica daquilo que é racional, que está de acordo com a razão”. Bombassaro (1992), alinhando-se a essa compreensão, toma o conhecimento em função da racionalidade, da razão, o que é corroborado por Bavaresco (2001, p. 3, inserção nossa) quando diz que Bombassaro (1992) toma "todo conhecimento [como] portador de racionalidade, porque está estruturado proposicionalmente. Não só as proposições podem ser consideradas racionais, mas também o homem, formador de expressões linguísticas, que dispõe do conhecimento, deve ser considerado racional".

O dogmatismo, por sua vez, é toda atitude que professa a capacidade do homem atingir a certeza absoluta. Filosoficamente, por oposição ao ceticismo, o dogmatismo é a atitude que consiste em admitir a possibilidade, para a razão humana, de chegar a verdades absolutamente certas e seguras (JAPIASSÚ; MARCONDES, 2001). Ele diz ainda da crença de que todo o conteúdo do pensamento está na razão, sendo assim, os juízos resultantes do pensamento proveniente da razão possuem necessidade lógica e validade universal.

Vemos nuances dessa compreensão no contexto da formação e do mesmo modo da formação continuada em Modelagem Matemática o que se evidencia na fala de Schön (2000), quando diz que os modelos de formação de professores vigentes "[...] seguem [...] o modelo da 'racionalidade técnica'", uma vez que seus

[...] alicerces científicos se fundam na tradição positivista, que ao invés de primar por encaminhamentos que levem em conta às multiplicidades características das práticas pedagógicas de cada professor, valorizam a busca por "[...] técnicas e métodos [...] universais" (ALMEIDA, 2001) que tomam essas mesmas práticas como universais e, portanto, passíveis de serem submetidas a processos generalistas de formação (MUTTI, 2016, p. 155-156).

Referindo-se ao distanciamento de modelos de formação nos quais o professor é concebido como técnico, as teorias mencionadas nos artigos levantados dizem da compreensão de que a formação dos professores deve seguir o princípio da racionalidade 
prática, entendida como uma atividade reflexiva. Alinhado a isso, Schön (2000) diz que o conhecimento profissional é entendido como um processo no qual um resultado inesperado pode levar à reflexão, reflexão-na-ação, dos problemas vivenciados na prática pedagógica do docente.

Corroborando a fala de Schön (2000), diversos autores, dentre os quais Imbernón (2010) e Alarcão (2010), têm defendido que a formação continuada deve seguir o princípio da racionalidade prática, a qual admite a capacidade inata do ser humano em pensar e refletir sobre a ação da prática docente.

Compreendemos, portanto, a necessidade da formação de professores e, destacadamente, a formação continuada em Modelagem Matemática, valorizar iniciativas que contemplem não apenas a aquisição de conhecimentos associados aos procedimentos que devem ser adotados durante o trabalho com a Modelagem Matemática, mas que prime por questões de cunho epistemológico. Ao dizermos isso referimo-nos à necessidade de possibilitar aos professores momentos de diálogos, discussão e reflexão, de tal modo que possam estabelecer relações entre os elementos que estão sendo estudados e as suas práticas pedagógicas. Em suma, significa que os professores possam participar dos processos de construção do conhecimento sobre Modelagem e não sejam meros coadjuvantes ou repetidores de práticas.

\section{Considerações}

A pesquisa que desenvolvemos, orientados pela interrogação: $O$ que se mostra, epistemologicamente, das discussões apresentadas pelos autores que discorrem sobre formação de professores, mencionados nos trabalhos sobre formação continuada publicados na CNMEM?, permitiu que empreendêssemos uma reflexão epistemológica acerca das diferentes compreensões sobre formação de professores, bem como sobre aspectos relacionados às discussões teóricas sobre a formação continuada de professores em Modelagem Matemática.

As compreensões que emergiram da análise realizada revelaram que, ainda que seja relevante à formação em Modelagem Matemática, pode não ser determinante para que essa tendência da Educação Matemática chegue à escola.

A ampliação da possibilidade de a Modelagem Matemática chegar à escola está associada, segundo o que discutimos nesse artigo, à valorização de iniciativas, no contexto da 
formação, que levem os professores a indagarem a sua própria prática, de modo que possam avaliar com clareza quais são os aspectos de sua prática que precisam ser modificados para que a Modelagem Matemática possa ser considerada e se precisam ser modificados.

Além disso, os trabalhos analisados apresentaram diferentes compreensões sobre a formação de professores, condição que entendemos ser favorecida pela importância da formação continuada na vida profissional docente. Isso revela distintas visões epistemológicas, isto é, distintos modos de produzir conhecimentos para a formação de professores em Modelagem Matemática. Indica que a jovialidade da pesquisa sobre formação de professores está sujeita à introdução de diferentes teorias "experimentais" para a formação. Revela, ainda, a existência de uma orientação pragmática na formação e de um paralelismo entre formação e sujeito.

Outro aspecto relevante em relação à formação continuada de professores é que ela deve se dar de forma espontânea, livre de obrigações para que o professor possa se sentir confortável e acolhido durante as reflexões, os diálogos e as discussões sobre as dificuldades encontradas na prática docente; e, além disso, para que ele se sinta confortável junto aos seus pares para uma possível mudança da sua prática pedagógica em sala de aula.

Podemos entender, portanto, que a existência de diferentes compreensões e distintas teorias sobre formação de professores em Modelagem Matemática revela que há a presença de diferentes visões epistemológicas sobre este tema, bem como a jovialidade dessa pesquisa, a qual está sujeita à influência de diferentes teorias.

\title{
Referências
}

ALARCÃO, I. Professores reflexivos em uma escola reflexiva. São Paulo: Cortez, 2010.

\author{
ALMEIDA, L. W. de A.; SILVA, K. P. da; VERTUAN, R. E. Modelagem matemática na \\ educação básica. São Paulo: Contexto, 2012.
}

BARBOSA, J. C. Modelagem Matemática e os professores: a questão da formação. Bolema, Rio Claro, v. 14, n. 15, p. 5-23, 2001.

BARBOSA, J. C. Modelagem Matemática na sala de aula. Perspectiva, Erechim (RS), v. 27, n. 98 , junho, 2003.

\footnotetext{
${ }^{3}$ Aquelas que ainda estão sendo construídas e, em muitos casos, tomadas como objeto de estudo de pesquisas voltadas para o contexto educacional.
} 
BARBOSA, J. C. Modelagem na Educação Matemática: Uma perspectiva. In: Encontro Paranaense de Modelagem em Educação Matemática, 1., Londrina. Anais... Londrina: UEL, 1 CD-ROM, 2004.

BAVARESCO, A. O Cenário epistemológico da modernidade e as novas configurações epistêmicas. In: SCHAEFER, Osmar Miguel; BAVARESCO, Agemir. Desenvolvimento social: conhecimento e trabalho. Pelotas: EDUCAT, 2001. p. 37-63.

BICUDO, M. A. V. Filosofia da Educação Matemática: fenomenologia, concepções, possibilidades didático-pedagógicas. São Paulo: Ed. UNESP, 2010.

BICUDO, M. A. V. Pesquisa qualitativa fenomenológica: interrogação, descrição e modalidades de análises. Pesquisa qualitativa segundo a visão fenomenológica. São Paulo: Cortez, 2011. p. 53-77.

BICUDO, M. A. V.; KLÜBER, T. E. Pesquisa em modelagem matemática no Brasil: a caminho de uma meta compreensão. Cadernos de Pesquisa, São Paulo, v. 41, n. 144, p. 904927, 2011.

BICUDO, M. A. V.; PAULO, R. M. Um Exercício Filosófico sobre a Pesquisa em Educação Matemática no Brasil. Bolema. Rio Claro, v. 25, n. 41, p. 251-298, 2011.

BISOGNIN, E.; BISOGNIN, V. Percepções de Professores sobre o Uso da Modelagem Matemática em Sala de Aula. Bolema, Rio Claro, vol. 26, n. 43 p. 1049-1079, ago. 2012.

BOMBASSARO, Luiz Carlos. Como se produz o conhecimento. Petrópolis, RJ: Vozes, 1992.

BURAK, D. A modelagem matemática e a sala de aula. In: I Encontro Paranaense de Modelagem em Educação Matemática - I EPMEM, 1. Londrina, 2004. Anais... Londrina: UEL, p. 1-10.

CARARO, E. F. F.; MUTTI, G. S. L.; KLÜBER, T. E. Formação Continuada em Educação Matemática no Estado do Paraná: Um olhar a partir de eventos ofertados pela SEED. EPREM - Encontro Paranaense de Educação Matemática, Ponta Grossa/PR, 2015.

FIORENTINI, D. Grupo de Sábado: Uma história de reflexão e escrita sobre a prática escolar em matemática. In: FIORENTINI, D.; CRISTÓVÃO, E. M. (Orgs.). Histórias e investigações de/em Aulas de Matemática. Campinas, SP: Alínea, 2006. p. 13-36.

GARNICA, A. V. M. Educação, Matemática, Paradigmas, Prova rigorosa e formação do professor. In: BICUDO, Maria Aparecida Viggiani; CAPPELLETTI, Isabel Franchi (Orgs.). Fenomenologia: Uma visão abrangente da Educação. São Paulo: Olho D’água, 1999, p. 105154. 
GARNICA, V. P. C.; BICUDO, M. A. V. Um estudo hermenêutico do texto de matemática. In: BICUDO, M. A. V.; ESPOSITO, V. H. C. Pesquisa qualitativa em Educação: Um enfoque fenomenológico. Piracicaba: Unimep, 1994. cap. 9, p. 95-102.

HESSEN, J. Filosofia dos valores. Coimbra: Armênio Amado, 1980.

HOUAISS, A. Dicionário de Língua Portuguesa. São Paulo: Objetiva, 2017. 200 p.

Disponível em: $<$ https://houaiss.uol.com.br/pub/apps/www/v3-2/html/index.php\#1 $>$. Acesso em: 15 ago. 2017.

IMBERNÓN, F. Formação permanente do professorado: novas tendências. São Paulo: Cortez, 2009.

IMBERNÓN, F. Formação continuada de professores. Porto Alegre: Artmed, 2010.

JAPIASSU, H.; MARCONDES, D. Dicionário Básico de Filosofia. 3. ed. Rio de Janeiro: Jorge Zahar, 2001.

KLÜBER, T. E. Atlas.ti como instrumento de análise me pesquisa qualitativa de abordagem fenomenológica. ETD-Educação Temática Digital, Campinas, SP, v. 16, n. 1, p. 5-23, jan. 2014.

KLÜBER, T. E. Formação de professores em Modelagem Matemática na Educação Matemática brasileira: questões emergentes. Educere et Educare, Universidade Estadual do Oeste do Paraná, Cascavel v. 12, n. 24, p. 1-11, 2017.

LUNA, A. V. de A. A Modelagem Matemática na Formação Continuada e a recontextualização pedagógica desse ambiente em salas de aula. 2012. 184 p. Tese (Doutorado) - Programa de Pós-graduação em Ensino, Filosofia e História das Ciências, Universidade Federal da Bahia, Salvador, 2012.

MARTINS, S. R. Formação Continuada de Professores em Modelagem Matemática na Educação Matemática: O sentido que os participantes atribuem ao grupo. 2016. 139 p. Dissertação (Mestrado em Educação) - Universidade Estadual do Oeste do Paraná, Foz do Iguaçu, 2016.

MUTTI, G. S. L. Práticas Pedagógicas da Educação Básica num Contexto de Formação Continuada em Modelagem Matemática na Educação Matemática. 2016. 236f. Dissertação (Metrado em Educação) - Universidade Estadual do Oeste do Paraná, Foz do Iguaçu, 2016.

OLIVEIRA, W. P. Modelagem Matemática nas Licenciaturas em Matemática das Universidades Estaduais do Paraná. 2016. 154 p. Dissertação (Mestrado em Educação) Curso de Programa de Pós-graduação em Educação, Universidade Estadual do Oeste do Paraná, Cascavel, 2016. 
PAULO, R. M.; AMARAL, C. L. C.; SANTIAGO, R. A. A pesquisa na perspectiva fenomenológica: explicitando uma possibilidade de compreensão do ser-professor de matemática. Revista Brasileira de Pesquisa em Educação em Ciências, Belo Horizonte, v. 10, n. 3, 2010.

SANTOS, W. S. Organização Curricular Baseada em Competência na Educação Médica. Revista Brasileira de Educação Médica. Rio de Janeiro, v. 35, n. 1, p. 86-92, jan./mar. 2011.

SCHÖN, D. Educando o profissional reflexivo: um novo design para o ensino e a aprendizagem. Porto Alegre: Artes Médicas, 2000.

SEVERINO, A. J. A pesquisa na pós-graduação em educação. Revista Eletrônica de Educação. São Carlos, SP: UFSCar, v. 1, n. 1, p. 31-49, set. 2007. Disponível em: http://www.reveduc.ufscar.br.

SILVEIRA, E.; CALDEIRA, A. D. Modelagem na Sala de Aula: resistências e obstáculos. Boletim de Educação Matemática. Rio Claro, v. 26, n. 43, p. 1021-1047, 2012.

TAMBARUSSI, C. M.; KLÜBER, T. E. A pesquisa em Modelagem Matemática na Educação Matemática: sobre as atividades de formação continuada em teses e dissertações.

REVEMAT. Florianópolis, v. 9, p. 38-56, 2014. Disponível em:

$<$ https://periodicos.ufsc.br/index.php/revemat/article/view/1981-1322.2014v9nespp38>.

Acesso em: 12 ago. 2017.

\section{Artigos analisados}

BENETTI, E. R. et al. Modelagem matemática: um estudo na viação Férrea de Santa Maria. Londrina: VI CNMEM, 2009. 13 p.

BONOTTO, D. L.; SCHELLER, M.; BIMBENGUT, M. S. Modelagem nas ciências e matemática: percepção de professores em formação continuada. São Carlos: IX CNMEM, 2015. 15p.

BRAGA, R. M.; LEDOUX, M. L. P; ROZAL, E. F.; ESPÍRITO SANTO, A. O. Experienciando a modelagem matemática em formação continuada. Santa Maria: VIII CNMEM, 2013. 11p.

CAMPOS, I. S.; LUNA, A. V. A. A relação entre Modelagem Matemática e a prática colaborativa na formação continuada de professores. Londrina: VI CNMEM, 2009. 18 p.

CHAVES, M. I. A; ESPÍRITO SANTO, A. O. Que professor se constrói com a modelagem Matemática? Londrina: VI CNMEM, 2009. 17 p. 
DIAS, M. R.; ALMEIDA, L. M. W. Um estudo sobre o desenvolvimento profissional do professor num programa de formação em Modelagem Matemática. Feira de Santana: IV CNMEM, 2005. 9 p.

FERREIRA, C. R.; BURAK, D. Considerações iniciais sobre um curso de Modelagem matemática em ambientes virtuais. Londrina:VI CNMEM, 2009. 13p.

GOMES, V. M. R et al. Modelagem matemática na formação Continuada: um olhar de professores sobre a questão do câncer de mama. Londrina: VI CNMEM, 2009. 14 p.

MARTINS, B. O. et al. Modelagem matemática e formação de professores: um mapeamento por meio dos periódicos nacionais. São Carlos: IX CNMEM, 2015. 9p.

MENDONÇA, L. O.; LOPES, C. E. Modelagem matemática no desenvolvimento profissional dos professores: reflexões e ações. Santa Maria: VIII CNMEM, 2016.

MENDONÇA, L. O.; LOPES, C. E. A ação pedagógica em ambientes de modelagem Matemática: uma discussão a partir da própria prática. Belém: VII CNMEM, 2011. 17p.

MOTA, R. O grupo colaborativo em modelagem matemática e a formação continuada de professores: possíveis transformações de uma prática. Santa Maria: VIII CNMEM, 2013. $10 \mathrm{p}$.

ROSA, C. C.; KATO, L. A. A modelagem matemática e a formação do professor reflexivo. Santa Maria: VIII CNMEM, 2013. 10p.

SANT'ANA, A. A.; SANT'ANA, M. F. Modelagem matemática em curso de formação continuada. São Carlos: IX CNMEM, 2015. 12p

SANTOS, L. R.; BISOGNIN, V. Modelagem matemática: experiência com o tema água em um curso de formação de professores. Santa Maria: VIII CNMEM, 2013. 13p.

SCHELLER, M.; BONOTTO, D. L.; BIEMBENGUT, M. S. Percepções dos professores em atividades de modelagem matemática na formação continuada. São Carlos: IX CNMEM, 2015. 16p.

SILVA, A. C. et al. Modelagem matemática na formação continuada de professores: uma análise a partir das produções do Enem 2013 e Eprem 2014. São Carlos: IX CNMEM, 2015. $16 \mathrm{p}$.

SILVA, J. N. D.; CARNEIRO, C. H. Modelagem matemática e a formação continuada de Professores da educação básica: Programa novos talentos. Belém: VII CNMEM, 2011. 13p. 